\title{
Synthesis and characterization of carbon nanospheres by catalytic CVD method
}

\section{Kadhim Rashid Gbashi}

Nanotechnology and Advanced Materials Research Center, University of Technology,

Baghdad, Iraq

E-mail: kazemrg@yahoo.com

\begin{abstract}
Carbon nanospheres (CNSs) were successfully prepared and synthesized by Catalytic Chemical Vapor Deposition (CCVD) by using camphor as carbon source only, over iron Cobalt (Fe-Co) saturated zeolite at temperature between $\left(700{ }^{\circ} \mathrm{C}\right.$ and $\left.900{ }^{\circ} \mathrm{C}\right)$, with different concentrations of camphor, and reaction time. The synthesized CNSs were characterized using Scanning Electron Microscopy (SEM), X-ray diffraction spectroscopy (XRD), and Fourier Transform Infrared (FTIR). The carbon spheres in different sizes between $100 \mathrm{~nm}$ and $1000 \mathrm{~nm}$ were investigated. This work has done by two parts, first preparation of the metallic catalyst and second part formation CNSs by heat treatment.
\end{abstract}

Key words

CVD, carbon nanospheres, catalytic.

\section{Article info.}

Received: May. 2017

Accepted: Jun. 2017

Published: Dec. 2017

\section{تركيب وتوصيف كرات الكاربون النانوية بواسطة طريقة الترسيب بالبخار الكيميائي المحفز كاظم رشيد كباثي مركز بحوث النانو تكنولوجي والمو اد المتقدمة، الجامعة التكنولوجية، بغداد، العر اق}

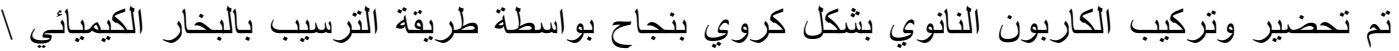

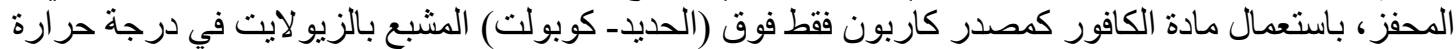

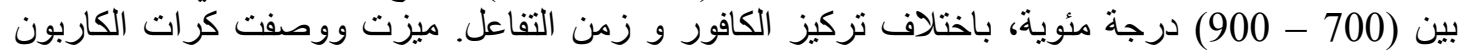

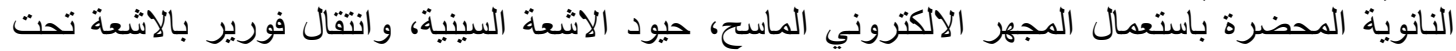

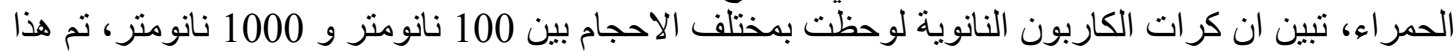

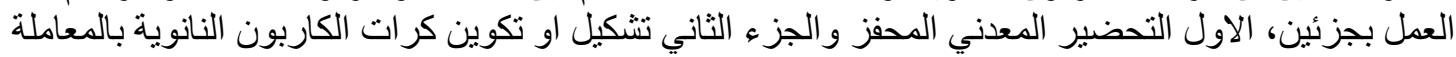

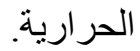

\section{Introduction}

As early as 1985, the discovery of bucky balls publicised a renewed interest in new forms of the carbon materials. These new carbon nanostructured materials (CNMs) from the $\mathrm{C}_{\mathrm{n}}$ family consist of carbon nanotubes (CNTs) [1-3], nanofilaments [4], nanocapsules [5], and the recently discovered carbon nanospheres (CNSs). CNSs have unique compounding or combination of chemical properties, deduced by $\mathrm{sp}, \mathrm{sp}^{2}$ and $\mathrm{sp}^{3}$ hybridized bonds, with the several structural arrangements, i.e. planar, linear, or tetra hedrical geometries [6]. The incomparable unique properties of CNSs make them an attractive material for a difference or variety of potential applications, such as energy-storage devices, lubricating materials; fabricate diamond films, super capacitors, catalyst supports, super conductivity, and special rubber additives [7, 8]. These properties of CNSs are similar to those of graphite or fullerenes, which 
include a large packing density, high temperature stability and excellent electrical conductivity [9]. The fluorescent and luminescent properties of carbon quantum dots (CQDs) are being explored as a low-toxicity as compared with metal-based quantum dots [10, 11]. Many techniques have been used to produce CNSs to date: the pitch's carbonization [12], arc discharge [13], the pyrolysis of hydrocarbons such as (toluene, styrene, benzene, ethane, and hexane), chemical vapor deposition (CVD) [14, 15], the use of micelles [16] and ultrasonic processing [17]. The cost of production in the synthetic methods is high and limits production in larger quantities. Most of the Carbon Nano Materials (CNMs) have been synthesized from precursors based on the fossil fuels such as acetylene and petroleum products. These precursors are destined to get depleted one day. Moreover, the cost of those raw materials is expected to increase day by day. Therefore, it is necessity to consider developing carbonaceous materials from the natural resources and recently, there have been reports for using carbon source like: camphor $\left(\mathrm{C}_{10} \mathrm{H}_{16} \mathrm{O}\right)$, turpentine oil $\left(\mathrm{C}_{10} \mathrm{H}_{16}\right)$, neem oil, eucalyptus oil $\left(\mathrm{C}_{10} \mathrm{H}_{18} \mathrm{O}\right)$ and palm oil $\left(\mathrm{C}_{67} \mathrm{H}_{127} \mathrm{O}_{8}\right)$ [18-25]. Chemical vapor deposition (CVD) is the most popular thermal decomposition of a hydrocarbon vapor is achieved in the presence of a metal catalyst. Hence, it is also known as thermal CVD or catalytic CVD (to distinguish it from many other kinds of CVD used for various purposes). If a solid hydrocarbon is to be used as the CNSs precursor, it can be directly kept in the low-temperature zone of the reaction tube. Volatile materials (ferrocene, camphor, naphthalene, etc.) directly turn from solid to vapor, and perform CVD while passing over the catalyst kept in the high-temperature zone.

\section{Experimental \\ 1. Preparation metal catalyst particles}

The popular metal catalyst ( $\mathrm{Fe}, \mathrm{Co}$, $\mathrm{Ni}$, other metals, such as, $\mathrm{Au}, \mathrm{Cu}, \mathrm{Ag}$, $\mathrm{Pt}, \mathrm{Pd}$ were also used to catalyze CNMs growth from various hydrocarbons. In this article, $0.1 \mathrm{~g}$ $\mathrm{Fe}\left(\mathrm{NO}_{3}\right)_{3} .9 \mathrm{H}_{2} \mathrm{O}$, and 0.1 g $\mathrm{Co}\left(\mathrm{NO}_{3}\right) \cdot 6 \mathrm{H}_{2} \mathrm{O}$, were dissolved in 20 $\mathrm{ml}$ ethanol using ultrasonic for $15 \mathrm{~min}$, after that add $1 \mathrm{~g}$ zeolite powder to the solution and sonicate the mixture for 1h. The solvent was then dried on hot plate at $80{ }^{\circ} \mathrm{C}$ for $8 \mathrm{~h}$ to get powder and ground into fine powder to be used as ready support (catalyst-impregnatedzeolite) for synthesis of CNSs.

\section{Synthesize of CNSs}

Fig. 1 shows experimental setup for the synthesized CNSs. The synthesis of CNSs was carried out by a CVD system at atmospheric pressure in horizontal tubular quartz $(1.85 \mathrm{~cm}$ inside diameter, and $130 \mathrm{~cm}$ long) from thermal decomposition of camphor vapor $\left(\mathrm{C}_{10} \mathrm{H}_{16} \mathrm{O}\right)$. Firstly, in zone (I), (2, 2.5, 3) g camphor was placed inside the quartz tube was vaporized at $225{ }^{\circ} \mathrm{C}$, secondly, vaporized camphor pyrolyzed over $0.5 \mathrm{~g}$ catalyst-impregnated-zeolite were placed in a ceramic boat at the center of the reactor tube in the furnace zone (II) at temperature (700-900) ${ }^{\circ} \mathrm{C}$, with argon as carrier gas at ambient pressure. After $(20,25,30)$ min reaction time, the furnaces were allowed to natural cooling to room temperature under argon flow and the carbon product on the zeolite was collected, weighed and characterized. 


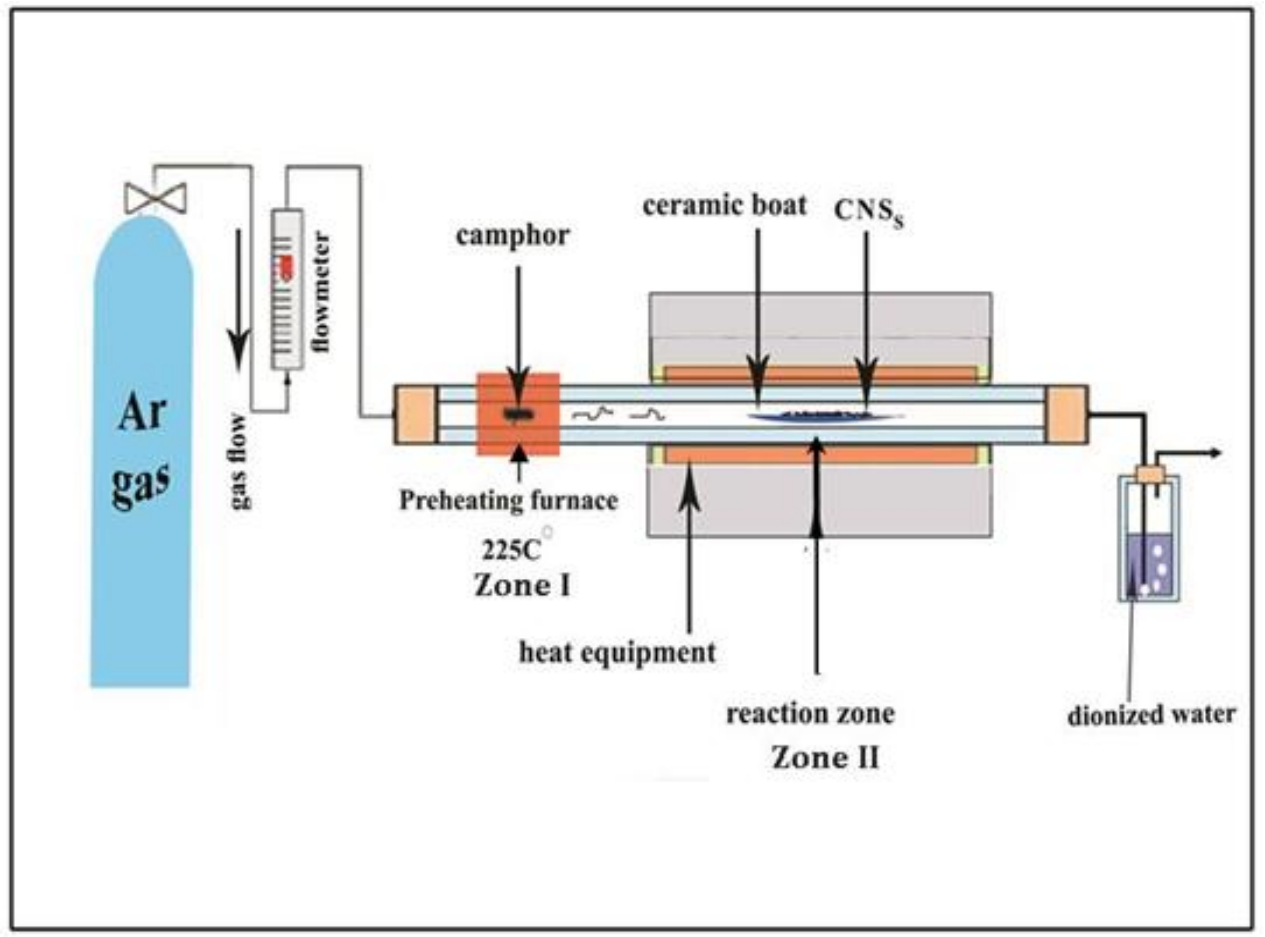

Fig. 1: The schematic experimental setup for the synthesis of CNSs.

\section{Factors interaction of growth} mechanism

The interaction and cohesion between suitable metal catalyst and decomposed carbon from camphor, (such a thermal decomposition is called pyrolysis), reaction times, temperatures and concentration of catalyst control the size of carbon nanospheres. Argon gas was followed at $60 \mathrm{sccm}$ for different time at $(700$,
800, and 900) ${ }^{\circ} \mathrm{C}$ and the collected products of CNSs were $(0.2,0.24$, and 0.27) g respectively, for different weight of impregnated zeolite with metal catalyst (Fig. 2). Fewer amount of dispersed carbon nanotubes can be obtained at $700{ }^{\circ} \mathrm{C}$, the growth mechanism is the Nano cluster shapes were periodically changing its shape from spherical to cylindrical to arrange the graphene as shown in the Fig. 5d.

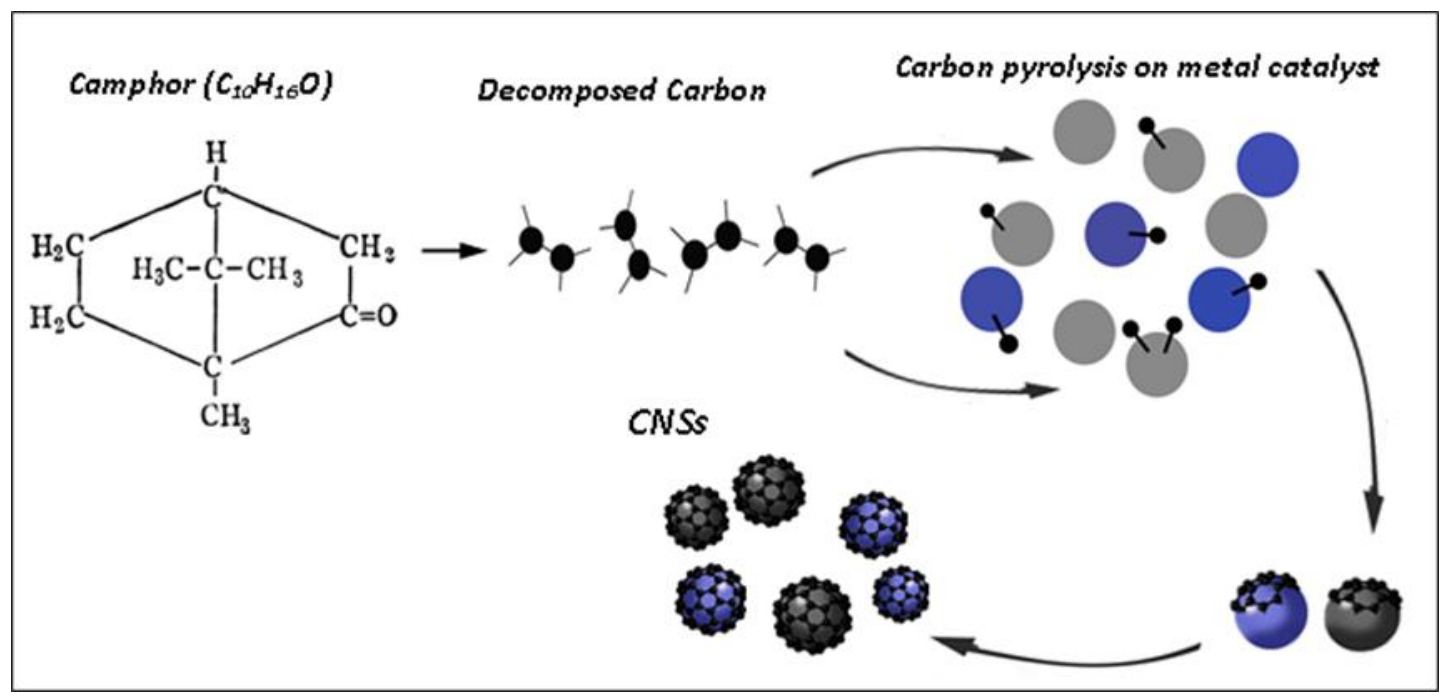

Fig. 2: Processes of catalytic CNSs growth mechanism. 
At temperature $700{ }^{\circ} \mathrm{C}$, the metal atoms clustered into bigger clusters leading to bigger CNSs, more carbon generate when increasing the concentration of camphor and the volume of carbon spheres increase with increasing temperature, hence more CNSs yield as showed in Table 1, and Fig. 3.

Table 1: Experimental condition and response for CNSs synthesized.

\begin{tabular}{|c|c|c|c|c|}
\hline $\begin{array}{c}\text { Experimental } \\
\text { run }\end{array}$ & $\begin{array}{c}\text { Temperature } \\
\left({ }^{\circ} \mathbf{C}\right)\end{array}$ & $\begin{array}{c}\text { Reaction time } \\
(\mathbf{m i n})\end{array}$ & $\begin{array}{c}\text { Camphor } \\
\text { Weight (g) }\end{array}$ & $\begin{array}{c}\text { Yield of CNSs } \\
(\mathbf{g})\end{array}$ \\
\hline 1 & 700 & 20 & 2 & 0.20 \\
\hline 2 & 800 & 25 & 2.5 & 0.24 \\
\hline 3 & 900 & 30 & 3 & 0.27 \\
\hline
\end{tabular}

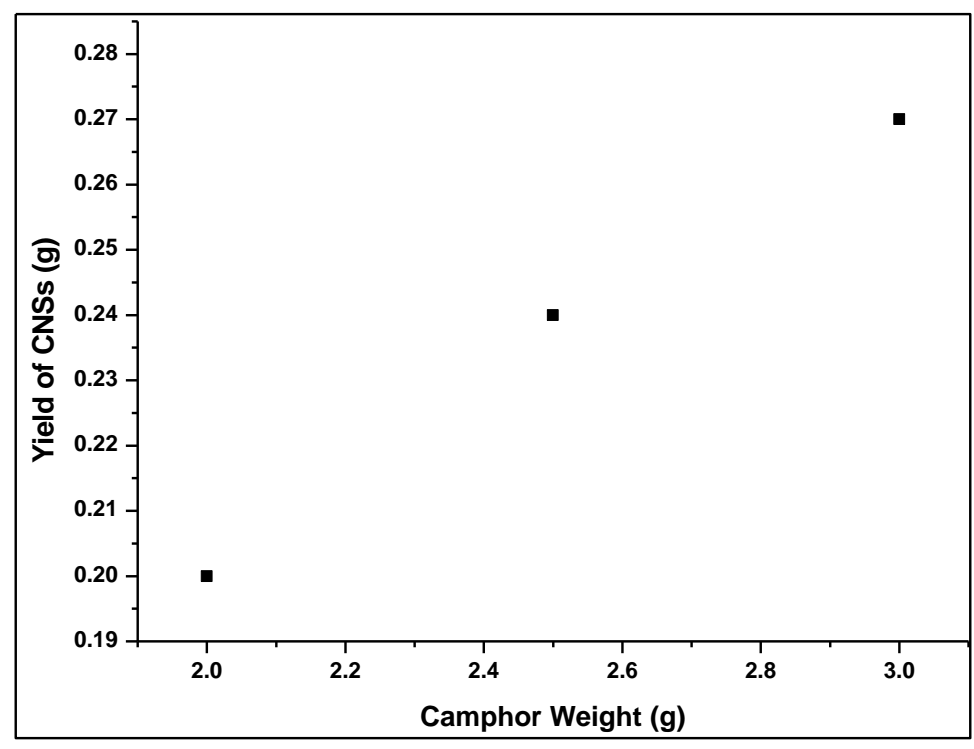

Fig. 3: Camphor weight vs yield.

\section{Characterization of CNSs}

$\mathrm{XRD}$ is widely used for the microstructural characterization of carbonaceous materials by peak analysis. The nature and phase (crystalline or amorphous structure) of the obtained product studied by powder x-ray diffraction analysis, which was performed by $\mathrm{x}$-ray 6000 diffractometer using the monochromatic high-intensity $\mathrm{Cu}$ (1.54060 ^) Voltage: $40.0 \mathrm{kV}$ Current: $30.0 \mathrm{~mA}$, Scan Range: 20.0000-
$60.0000 \mathrm{deg}$, A typical XRD pattern of the synthesized products is shown in Fig. 4. This figure shows peaks that correspond to the graphitic lattice, (002), (101) and (004) reflections of hexagonal graphite (JCPDS \# 25-0284 Graphite, Carbon). XRD reflections correspond to $2 \theta=(26.4,43.4$, and 54.6) degree respectively, these patterns reveals a characteristic pattern of graphitized carbon. The high intensity of the sharpness of the peak (002) suggests that the carbon 
nanospheres (CNSs) formed is showing strong crystalline structures. This pattern also indicates a high degree of crystallinity which suggests a low content of amorphous carbon and the presence of impurities drawn from the catalyst, usually iron particles [26]. The peak located at $2 \theta$ angle of $\sim 43.4$, with the low intensity as showed is an indication of the quality of carbon nanospheres present in the synthesized product and can be readily assigned to (101) diffraction of graphene and is a signature of the hexagonal graphite lattice of multi-walled CNTs present.

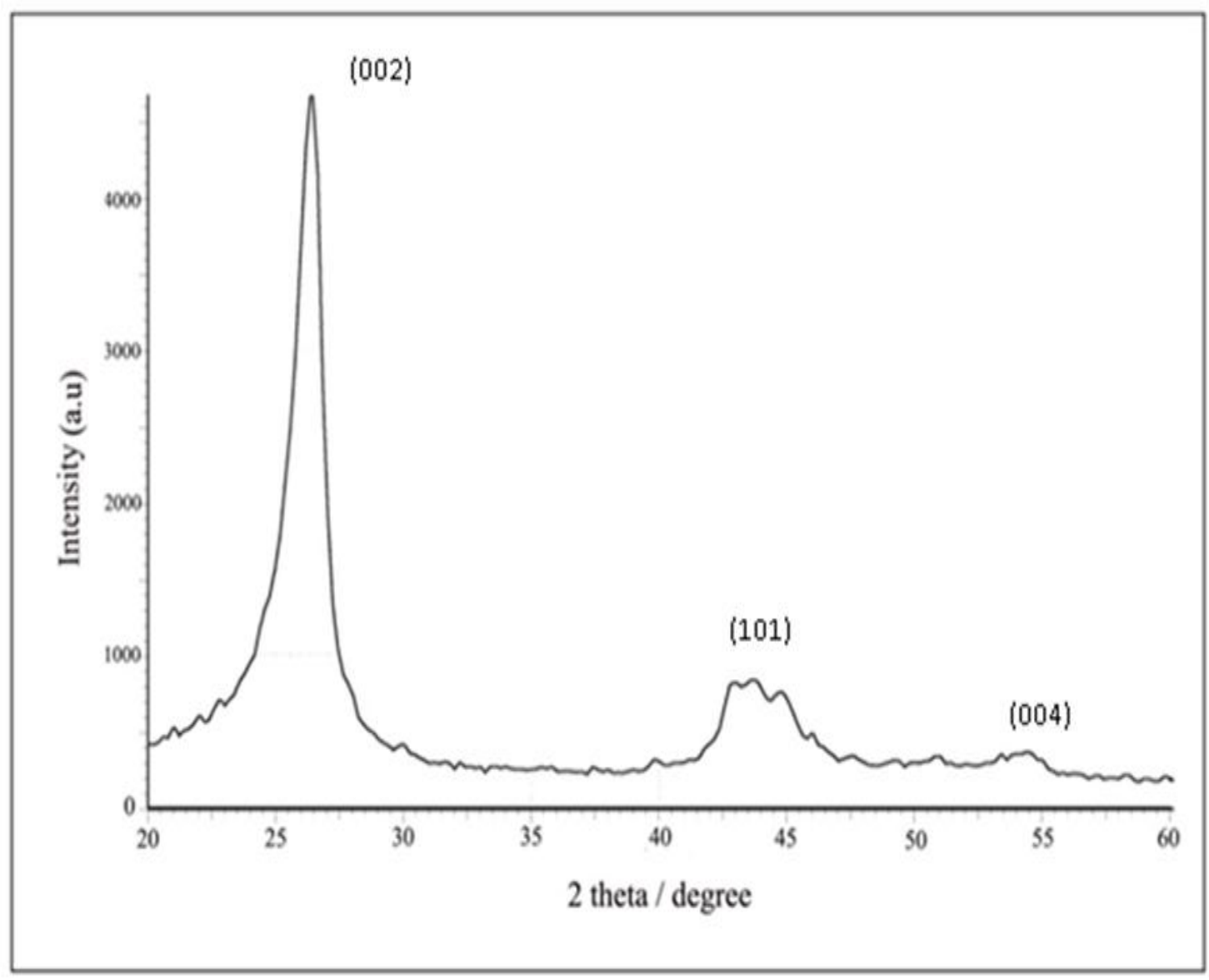

Fig. 4: XRD the spectroscopy of graphite nano-powders obtained by CCVD.

The SEM micrograph of the prepared carbon nanospheres is presented in Fig. 5. The surface morphology of the carbon deposit obtained is seen to form several spherical carbon nanomaterials which could be called carbon nanospheres. SEM images of the collected products show monodispersed carbon spheres over supported zeolite powder. These carbon spheres have diameters of $100-1000 \mathrm{~nm}$. The micrograph reveals the presence of (hard spherical) carbon spheres having a smooth surface morphology. 

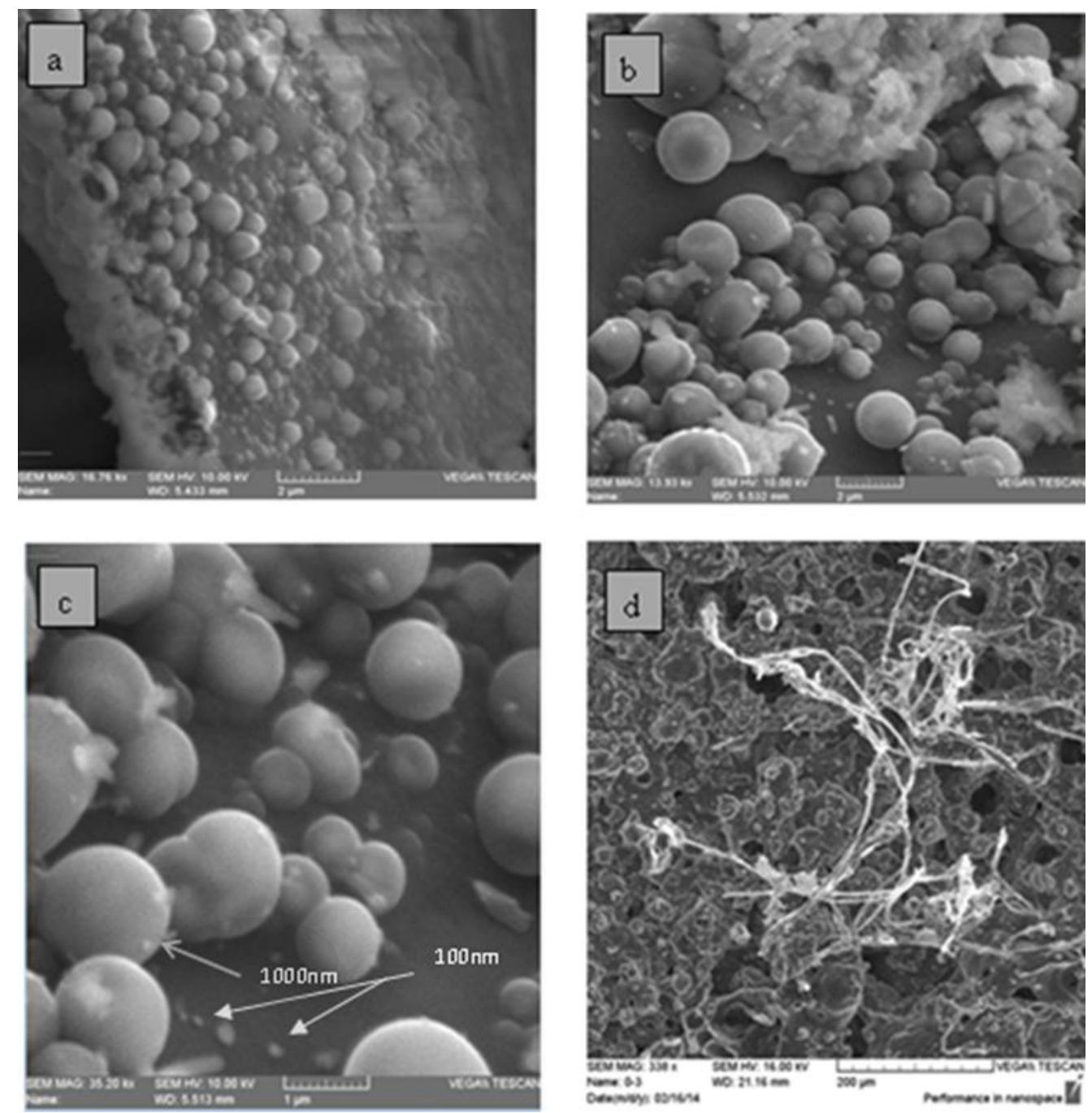

Fig. 5: Electron microscopic images of synthesized CNSs $a, b, c 800^{\circ} \mathrm{C}$ with different scale bar and d-reacted catalyst as CNTs with $700^{\circ} \mathrm{C}$.

Infrared spectral data are used to identify the functional groups of the carbon nanospheres (CNSs) formed (Fig.6), FT-IR spectra were collected on powder samples the peaks are hardly observed at $3290-3142 \mathrm{~cm}^{-1}$ assigned to (C-H) $\mathrm{sp}$ and $\mathrm{sp}^{2}$ aromatic hydrocarbon, the peaks at 2981 and $2841 \mathrm{~cm}^{-1}$ are assigned as $\mathrm{CH}_{2}$ asymmetric stretching vibration and $\mathrm{CH}_{3}$ symmetric stretching vibration respectively. The peak visible at $2393 \mathrm{~cm}^{-1}$ due to $\mathrm{C} \equiv C$, the very small absorption in the range at 1730$1606 \mathrm{~cm}^{-1}$ due to stretching of $\mathrm{C}=\mathrm{C}$ bonds in the graphene layers $(v \mathrm{C}=\mathrm{C})$. The peak at $1450 \mathrm{~cm}^{-1}$ assigned to $\mathrm{C}-\mathrm{C}$ skeleton and $\mathrm{C}-\mathrm{H}$ bending modes. the bands in the range of 1300 to $1000 \mathrm{~cm}^{-1}$ indicating few $\mathrm{C}-\mathrm{OH}$ stretching and $\mathrm{OH}$ bending vibrations and implying few residual hydroxyl groups, 1122$947 \mathrm{~cm}^{-1}$, the FT-IR spectra exhibit bands corresponding to $\mathrm{CH}_{3}$ groups [27, 28]. 


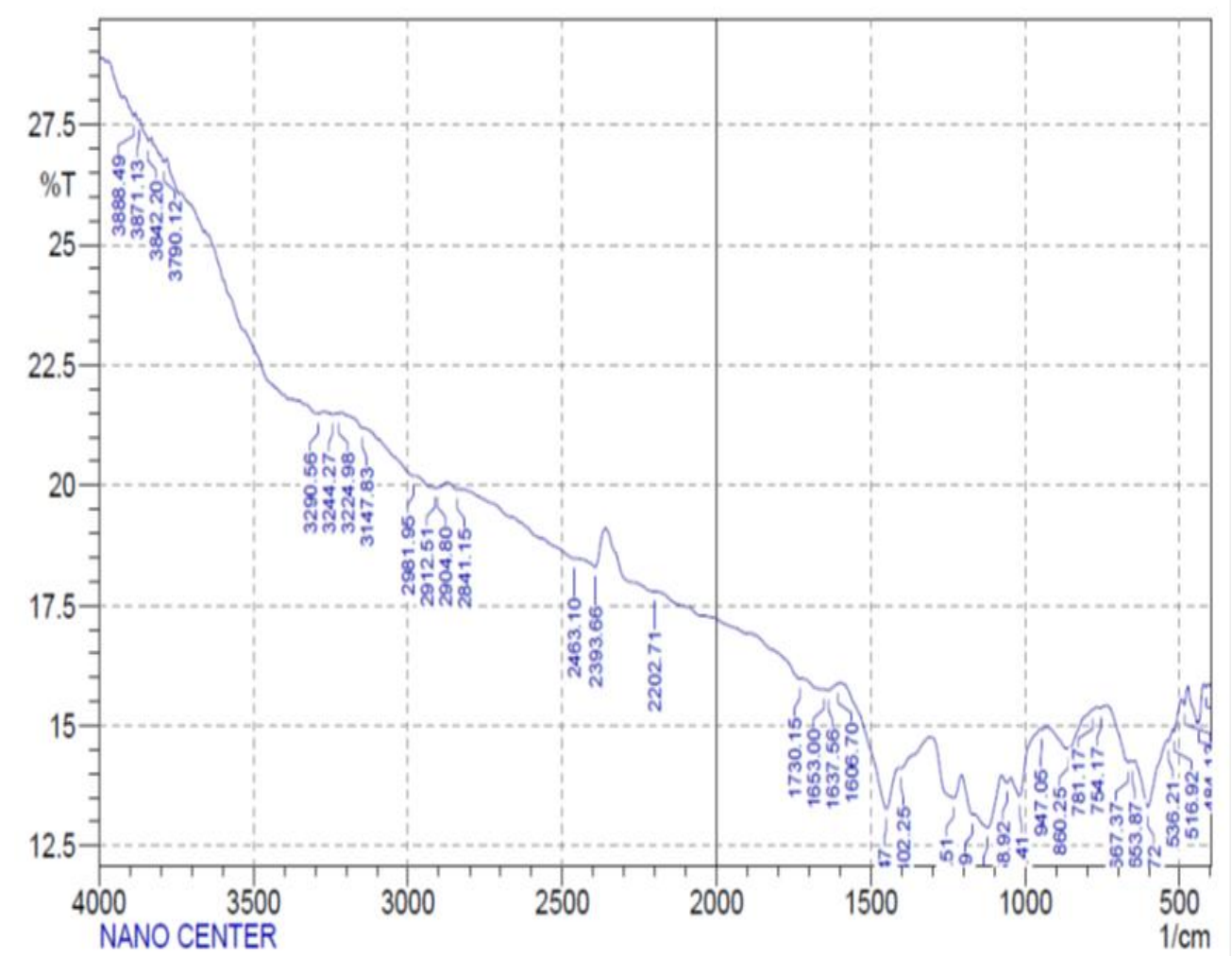

Fig. 6: FTIR spectra of synthesis of CNSs.

\section{Conclusions}

CNSs have been successfully synthesized from camphor decomposition at optimum temperature $800{ }^{\circ} \mathrm{C}$ by a catalytic CVD method over zeolite powder supported $\mathrm{Fe} / \mathrm{Co}$ nanoparticles as catalysts prepared by wet impregnation method. From the synthesis of carbon materials it is possible to obtain spherical carbon particles, with diameter in the (1001000) $\mathrm{nm}$ range, but also the presence more of larger particles can be detected. The product obtained was characterized by X-ray diffraction, FTIR spectroscopy and SEM.

\section{Acknowledgment}

The author is grateful to Prof. Haider and assist. Prof. Faisal, for their support and valuable discussion.

\section{Refrences}

[1] HW. Kroto, JR. Heath, SC. O'Brien, RF. Curl, RE. Smalley, C60:
Buckminister fullerene. Nature, 318 (1985) 162-163.

[2] S. Iijima Helical, Nature, 354 (1991) 56-58.

[3] G. E. J. Poinern, D. Parsonage, T. B. Issa, M. K. Ghosh, E. Paling, P. Singh, International J. of Engineering Science and Technology, 2, 8 (2010) 13-24.

[4] Lee, Seung-Yup, Mami Yamada, Mikio Miyake. Science and Technology of Advanced Materials, 6, 5 (2005) 420-426.

[5] Sano, Noriaki, Hiroshi Akazawa, Takeyuki Kikuchi, Tatsuo Kanki. Carbon, 41, 11 (2003) 2159-2162.

[6] R. C. Powles, N. A. Marks, D. W. M. Lau. Physical Review B 79, 7 (2009) 075430.

[7] Yang, Ruizhi, Xinping Qiu, Huairuo Zhang, Jianqi Li, Wentao Zhu, Zhaoxiang Wang, Xuejie Huang, Liquan Chen., Carbon, 43, 1 (2005) 11-16.

[8] Wang, Yong, Fabing Su, Colin D. Wood, Jim Yang Lee, Xiu Song 
Zhao, Industrial \& Engineering Chemistry Research 47, 7 (2008) 2294-2300.

[9] Yuan, Dingsheng, Jingxing Chen, Jianghua Zeng, Sanxiang Tan. Electrochemistry Communications, 10 , 7 (2008) 1067-1070.

[10] Sun, Ya-Ping, Bing Zhou, Yi Lin, Wei Wang, KA. Shiral Fernando, Pankaj Pathak, Mohammed Jaouad Meziani, Journal of the American Chemical Society, 128, 24 (2006) 7756-7757.

[11] Liu, Haipeng, Tao Ye, Chengde Mao., Angewandte Chemie International Edition, 46, 34 (2007) 6473-6475.

[12] Qu, Jiao, Qian Zhang, Yunsheng Xia, Qiao Cong, Chunqiu Luo. Environmental Science and Pollution Research, 22, 2 (2015) 1408-1419.

[13] W. M. Qiao, Y. Song, S. Y. Lim, S. H. Hong, S. H. Yoon, I. Mochida, T. Imaoka, Carbon, 44, 1 (2006) 187-190. [14] Serp, Ph, R. Feurer, Ph Kalck, Y. Kihn, J. L. Faria, J. L. Figueiredo, Carbon, 39, 4 (2001) 621-626.

[15] Qian, Hai-sheng, Feng-mei Han, Bing Zhang, Yan-chuan Guo, Jun Yue, Bi-xian Peng, Carbon, 42, 4 (2004) 761-766.

[16] BJ. Kim, JY. Chang, Macromolecules, 39, 1 (2006) 90-94. [17] Wang, Zhenxia, Liping Yu, Wei Zhang, Zhiyuan Zhu, Guowei He, Yi Chen, Gang Hu., Physics Letters A 307, 4 (2003) 249-252.
[18] M. Sharon, W. K. Hsu, H. W. Kroto, D. R. M. Walton, A. Kawahara, T. Ishihara, Y. Takita. Journal of power sources, 104, 1 (2002) 148-153.

[19] A. K. Chatterjee, Maheshwar Sharon, Rangan Banerjee, Michael Neumann-Spallart, Electrochimica Acta, 48, 23 (2003) 3439-3446.

[20] Afre, A. Rakesh, T. Soga, T. Jimbo, Mukul Kumar, Y. Ando, M. Sharon. Chemical Physics Letters, 414, 1 (2005) 6-10.

[21] Afre, A. Rakesh, T. Soga, T. Jimbo, Mukul Kumar, Y. Ando, M. Sharon, Prakash R. Somani, M. Umeno., Microporous and Mesoporous Materials, 96, 1 (2006) 184-190.

[22] Kumar, Mukul, Yoshinori Ando., Chemical Physics Letters, 374, 5 (2003) 521-526.

[23] Kumar, Mukul, Yoshinori Ando. Diamond and Related Materials, 12, 3 (2003) 998-1002.

[24] Kumar, Mukul, Yoshinori Ando., Carbon, 43, 3 (2005) 533-540.

[25] Ghosh, Pradip, Rakesh A. Afre, T. Soga, T. Jimbo., Materials Letters, 61, 17 (2007) 3768-3770.

[26]. Wu, Lina, Feng Yan, Huangxian Ju., Journal of Immunological Methods, 322, 1 (2007) 12-19.

[27] Liu, Shi-Xiong, Shan Gao. Polyhedron, 17, 1 (1998) 81-84.

[28] M.R. Maurya, Coord. Chem. Rev. 237 (2003) 163-181. 